\title{
Correction to: 'I decided to attend to him because it's my duty': Student Nurses perception and attitude towards care of older adults
}

Priscilla Yeye Adumoah Attafuah ${ }^{1,2^{*}}$, Ninon Amertil ${ }^{3}$, Jacob Owusu Sarfo ${ }^{4}$, David Atsu Deegbe ${ }^{1}$, Delight Nyonator ${ }^{1}$, Caleb Amponsah-Boama ${ }^{3}$ and Aaron A. Abuosi ${ }^{5}$

Correction to: BMC Med Educ 22, 23 (2022)

https://doi.org/10.1186/s12909-021-03090-z

Following publication of the original article [1], we have been informed that the authors were incorrectly affiliated.

The author affiliation has been updated above and the original article [1] has been corrected.

\begin{abstract}
Author details
${ }^{1}$ School of Nursing and Midwifery, University of Ghana, Legon, Ghana.

${ }^{2}$ Department of Health Services Research and Care and Public Health Research Institute (CAPHRI), Maastricht University, Maastricht, the Netherlands. ${ }^{3}$ School of Nursing and Midwifery, Valley View University, Oyibi, Ghana. ${ }^{4}$ Department of Health, Physical Education and Recreation, University of Cape Coast, Cape Coast, Ghana. ${ }^{5}$ Department of Public Admin and Health Services, University of Ghana Business School, Legon, Ghana.
\end{abstract}

Published online: 26 January 2022

\section{Reference}

1. Attafuah, et al. 1 decided to attend to him because it's my duty': Student Nurses perception and attitude towards care of older adults. BMC Med Educ. 2022;22:23. https://doi.org/10.1186/s12909-021-03090-z.

The original article can be found online at https://doi.org/10.1186/s12909021-03090-z.

\section{*Correspondence: pyaattafuah@ug.edu.gh}

1 School of Nursing and Midwifery, University of Ghana, Legon, Ghana

Full list of author information is available at the end of the article 